\title{
EFFECT OF PHASE CHANGE MATERIAL ON TEMPERATURE IN A ROOM FITTED WITH A WINDCATCHER
}

\author{
Peter Abdo, B. Phuoc Huynh, Ali Braytee and Rahil Taghipour \\ Faculty of Engineering and Information Technology, \\ University of Technology Sydney, \\ Sydney, NSW, Australia
}

\begin{abstract}
Global warming and climate change have been considered as major challenges over the past few decades. Sustainable and renewable energy sources are nowadays needed to overcome the undesirable consequences of rapid development in the world. Phase change materials (PCM) are substances with high latent heat storage capacity which absorb or release the heat from or to the surrounding environment. They change from solid to liquid and vice versa. PCMs could be used as a passive cooling method which enhances energy efficiency in buildings. Integrating PCM with natural ventilation is investigated in this study by exploring the effect of phase change material on the temperature in a room fitted with a windcatcher. A chamber made of acrylic sheets fitted with a windcatcher is used to monitor the temperature variations. The dimensions of the chamber are $1250 \times 1000 \times 750 \mathrm{~mm}^{3}$. Phase change material is integrated respectively at the walls of the room, its floor and ceiling and within the windcatchers inlet channel. Temperature is measured at different locations inside the chamber. Wind is blown through the room using a fan with heating elements.
\end{abstract}

\section{INTRODUCTION}

The majority of the world's population now lives in cities [1] which has led to an increase in the urban heat island effect, increased air pollution [2-4] and consequently a large increase in the energy demand required by mechanical ventilation systems [5-7]. Decreasing the energy consumption in the building sector by using innovative solutions such as using green walls which help enhance the indoor air quality and reduce the temperature of their surroundings have been the subject of many recent studies [8-10]. Integrating phase change material in building envelops also shows promise as a sustainable solution which contributes to decreasing the cooling demand and energy consumption $[11,12]$.

Phase Change Materials (PCMs) absorb thermal energy during the day as they transform from solid to liquid, hence cooling the surrounding air temperature. During the night, PCMs release their energy as they change back to solid state. PCMs could be an efficient addition to passive cooling systems and they are directly related to building energy efficiency.

Phase change materials use the latent heat properties of materials to store energy, which is charged and discharged by the passing air. The working principle of PCM consists of two modes of operation, the charging and the discharging process [13].

Charging process, or solidification of PCM, takes place during night time when ambient temperature is lower than the room temperature. The cool ambient air flows over the liquid PCM and removes its heat [14]. Figure 1 [14] shows the working principle of PCMs. 
Discharging process, or cooling of the air, happens when the room temperature rises above a certain limit. The cold stored that has been stored in the solid PCM is then discharged to the passing hot air. The air in the living space is thus cooled down by the PCM [14].

Melting point of PCM is critical to achieve efficient PCM design [14]. The cooled air temperature resulting from the discharging process should be within the human comfort limits in summer $\left(23{ }^{\circ} \mathrm{C}\right.$ to $\left.27{ }^{\circ} \mathrm{C}\right)$. As such the PCM melting temperature should be between $19{ }^{\circ} \mathrm{C}$ and $24^{\circ} \mathrm{C}$ [15].
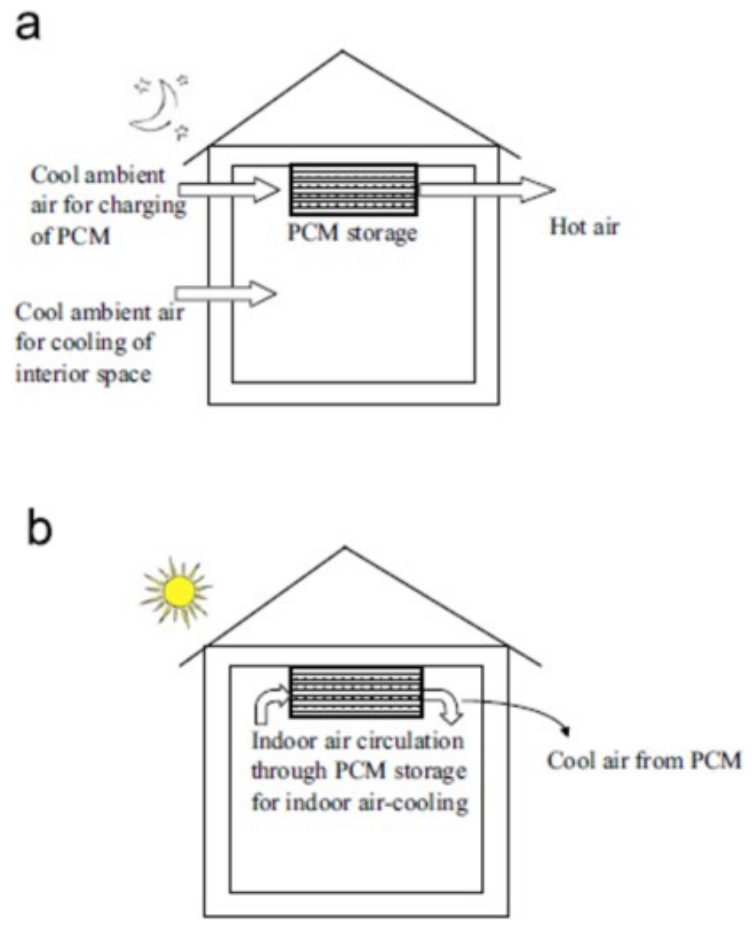

Figure 1. PCM working principle [14] a) night time charging process, b) day time discharging process

PCMs are of different types, they are classified as organic, inorganic and eutectic. Organic PCMs are either paraffins or non-paraffins [16], while inorganic PCMs are either hydrated salts or metallic. An eutectic is a composition of two or more components [17]. Eutectics PCMs are subdivided into organicorganic, organic-inorganic and inorganic-inorganic [18]. PCM products come in different performance temperatures and densities based on the manufacturer and the application conditions [13]. They are not a replacement for insulation. Figure 2 shows some different PCM products.

The actual amount of PCM to be used depends on the quality of the build (such as the insulation, tightness, quality, size, and orientation of windows), as well as on the building design and its orientation. Basically the more PCM used the better performance is obtained.
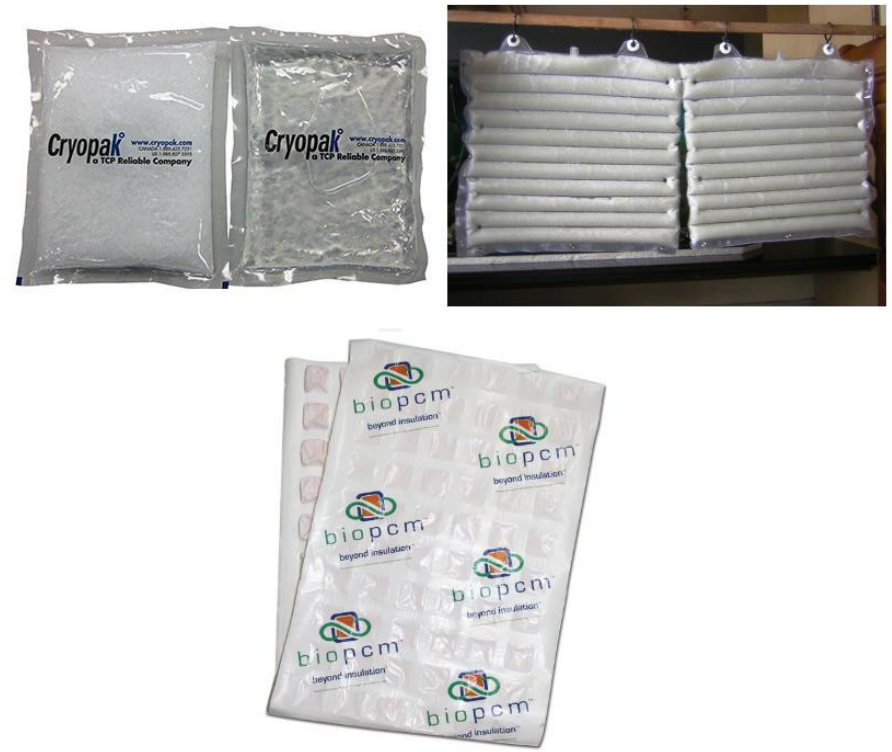

Figure 2. Different PCM products

According to Verna et al. and Zhang et al. [19, 20], 73\% of the regions where PCM is used or studied is in Europe while very few are located in Asia [14]. Most of these studies are located (especially in Europe) where energy efficiency, energy conservation and climate change have recently gained a lot of concern. The integration of PCMs in buildings as a passive approach to improve their energy efficiency has significantly been increasing [13]. Many extensive review articles related to PCMs and their applications have been published which indicates that the interest in implementing them is rising $[18$, 21]. Most of these reviews focus on the characterization and classification of PCMs and on their active or passive applications in buildings [22].

Akeiber et al [22] reviewed PCM for sustainable passive cooling in buildings and concluded that the organic type particularly the paraffin is the most appropriate due to its price, stability and high heat of fusion however it has low thermal conductivity. The study proposed that integrating PCM with natural ventilation must be explored as a sustainable system, such as the combination of PCM with windcatchers could be promising in providing both cooling and ventilation.

Ramakrishnan et al [23] analyzed the performance enhancement of phase change material in naturally ventilated buildings and concluded that optimizing the PCM based on its efficiency is the most appropriate approach to obtain maximum indoor thermal comfort. The authors found that for some Australian cities such as Melbourne, Sydney, Perth and Brisbane, PCM with $3-5^{\circ} \mathrm{C}$ higher phase change temperatures compared to the average outdoor temperature is required to achieve the highest indoor thermal comfort. Their study also concluded that thicker PCM enhances thermal comfort while it reduces its cooling efficiency. 
Alvarez et al [24] have studied the integration of PCM for natural cooling of buildings and concluded that there are drawbacks in the way things have been done in PCM. Mosaffa et al [25] developed a computer model for the evaluation of a multiple PCM unit where its performance is studied numerically. Waqas and Ud Din [14] have reviewed the phase change material storage for free cooling of buildings. Soares et al [13] provided a comprehensive review in relation to how and where PCMs are used in passive cooling systems and how they are related to building energy efficiency. It was concluded that PCMs contribute to increase the indoor thermal comfort and in the reduction of $\mathrm{CO}_{2}$ emissions associated with heating and cooling.

Hughes and Ghani [26] investigated the performance of windcatcher under various wind-direction and wind velocity in order to provide recommended amount of fresh air to the building. The results show that windcatchers can provide acceptable amount of fresh air to the building even if the outdoor wind velocity is low. However, this research did not investigate the ability of windcatcher to provide acceptable thermal comfort for occupants. The performance of windcatchers has been subject of several previous computational studies [27-30] using two dimensional and three dimensional analysis.

This study will investigate the effect of PCM on the temperature inside a room fitted with a windcatcher.

\section{MATERIALS AND METHODS}

An experimental set up including an acrylic chamber fitted with a windcatcher was incorporated with phase change material and the temperature variations inside the chamber were monitored via BME sensors.

A $12 \mathrm{~mm}$ acrylic sheets chamber of dimensions $1250 \mathrm{x} 1000 \mathrm{x}$ $750 \mathrm{~mm}^{3}$ has been used in this study to monitor the effect of PCM. The two sheets along the length of the chamber (right and left hand side) with dimensions of $1250 \mathrm{~mm} \times 750 \mathrm{~mm}$ had several $12.7 \mathrm{~mm}$ holes. Some of these holes were used to insert the sensors cables and probes into the chamber. The unused holes were closed with special plugs. A two sided windcatcher with two canal bottom shape is fitted on the roof of the acrylic chamber. The canals are curved with squared inlet/outlet shape and dimensions of $160 \times 160 \mathrm{~mm}^{2}$. The inlets are $400 \mathrm{~mm}$ above the roof of the chamber and the canals descend by only $100 \mathrm{~mm}$ inside the room. Figure 5-4 shows a three dimensional drawing of the acrylic chamber including the fitted two sided windcatcher along with their related dimensions.

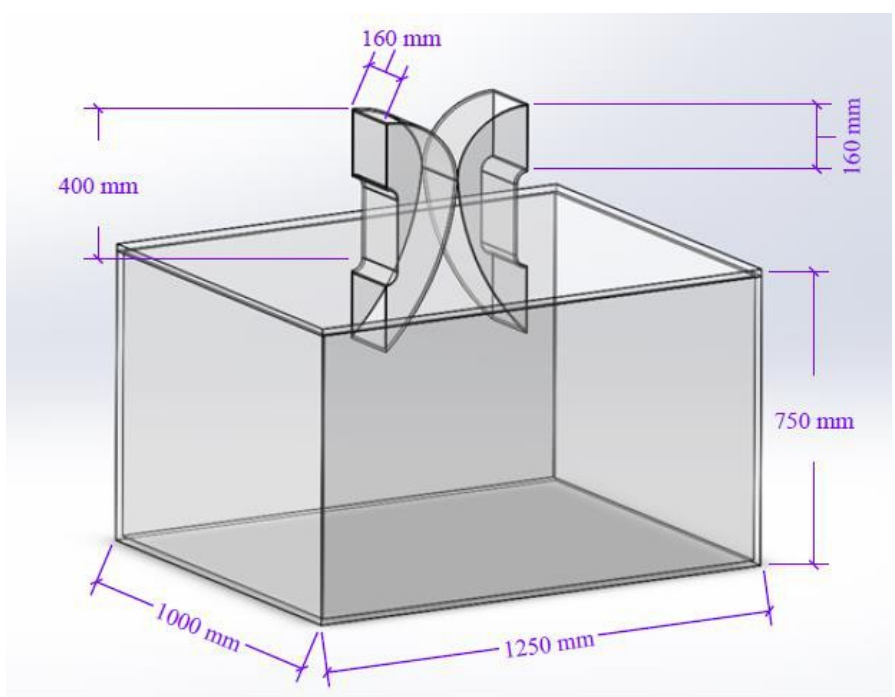

Figure 3. Three dimensional drawing of the acrylic chamber fitted with a two sided windcatcher

Plywood of $6 \mathrm{~mm}$ thickness has been used as additional insulation for the acrylic chamber. Different plywood sheets have been cut to fit the chamber walls, floor and roof.

The phase change material used in this study is Bio PCM M51 Q24. Each carton contains 6 sheets (shown in figure 4) of dimensions $1050 \mathrm{~mm} \times 480 \mathrm{~mm}$ with a total weight of $9 \mathrm{Kg}$ of active ingredients and a total energy capacity of $459 \mathrm{Wh} /$ carton. Each sheet has seven pouches $110 \mathrm{~mm}$ x $300 \mathrm{~mm}$. Its melt band is $20-24{ }^{\circ} \mathrm{C}$ and it contains a fire retardant and a gelling agent. The energy generated from Bio PCM is approximately $4 \mathrm{KWhr}$.

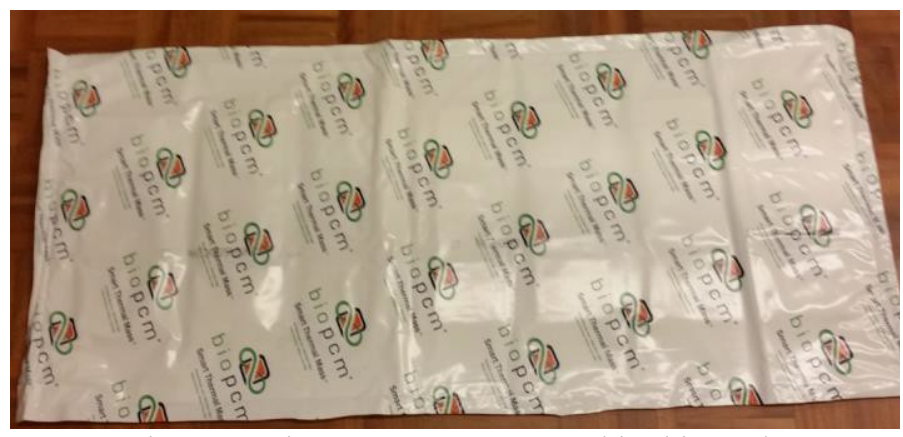

Figure 4. Bio PCM M51 Q24 used in this study

The phase change sheets have been placed at different locations in the chamber for testing its effect. Mainly PCM was placed on the floor, attached to the walls, and covered the ceiling. Figure 5 shows the chamber with full coverage of PCM, floor, wall and ceiling (without the insulation for better visualization). In addition, some experiments included PCM placed in the inlet windtunnel of the windcatcher as shown in Figure 6. 


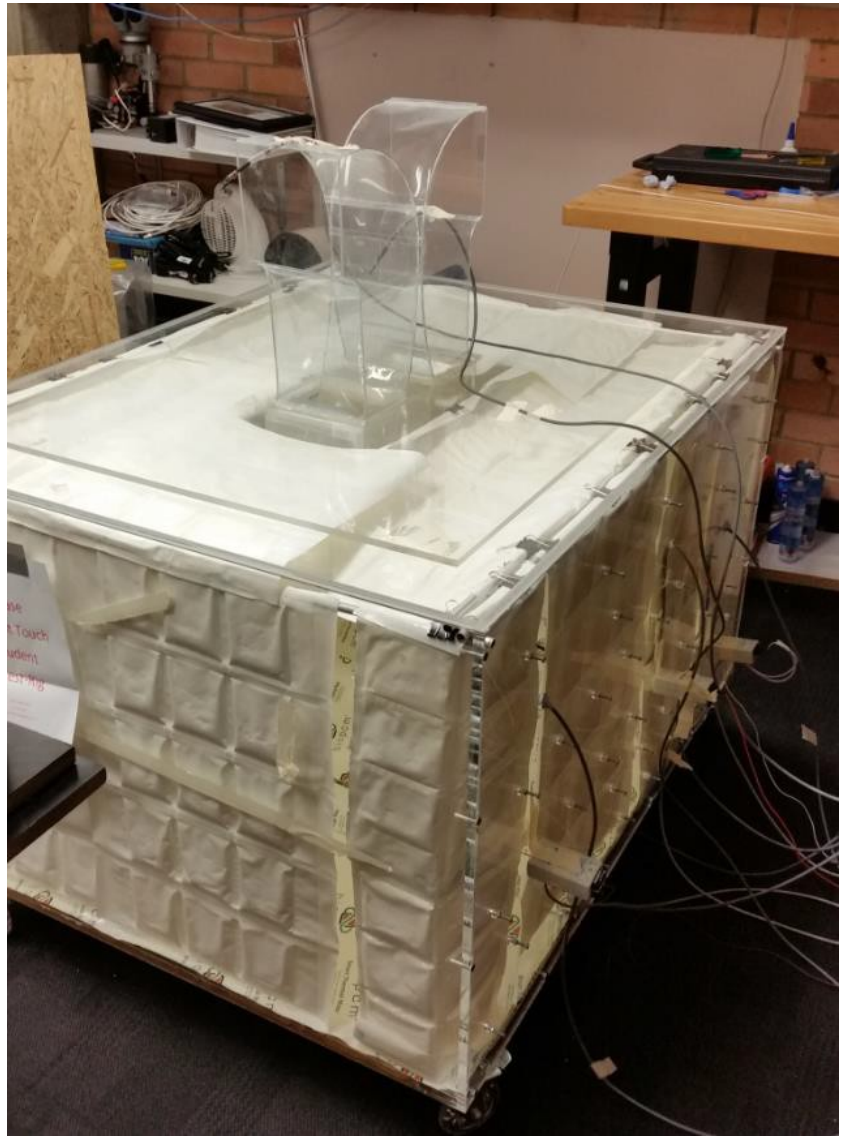

Figure 5. Chamber with PCM placed on floor, walls and covering the ceiling

A hot box, fan with heating elements manufactured by Thermal Electric Elements Australia has been used to generate air flow at different speeds and at different temperatures. The hot box has different stages, each stage would add about $7{ }^{\circ} \mathrm{C}$ to the air temperature. The hot box required three phase connection and was placed on a table $0.92 \mathrm{~m}$ high as shown in Figure 7.

Figure 7 shows the set up used to generate air flow. The hot air blown by the Hot Box fan was directed to the acrylic chamber through two ducts separated by a straightener. Both ducts have similar dimensions, their length is $500 \mathrm{~mm}$ and the internal dimensions of the ducts openings are $340 \mathrm{~mm} \times 340 \mathrm{~mm}$. The distance between the duct outlet and the windcatcher's opening is $850 \mathrm{~mm}$.

Temperature variations were monitored via BME 280 sensors (Temperature, Pressure and Humidity). A total of eight BME sensors were used and their output connected to a Raspberry Pi 2 . The software was set to record readings every 15 seconds and the data was exported to excel. Graphs showing the measurement were also downloaded from the software. During a course of recording, temporal readings varied by less than $3 \%$ about an average value for all of the sensors used.

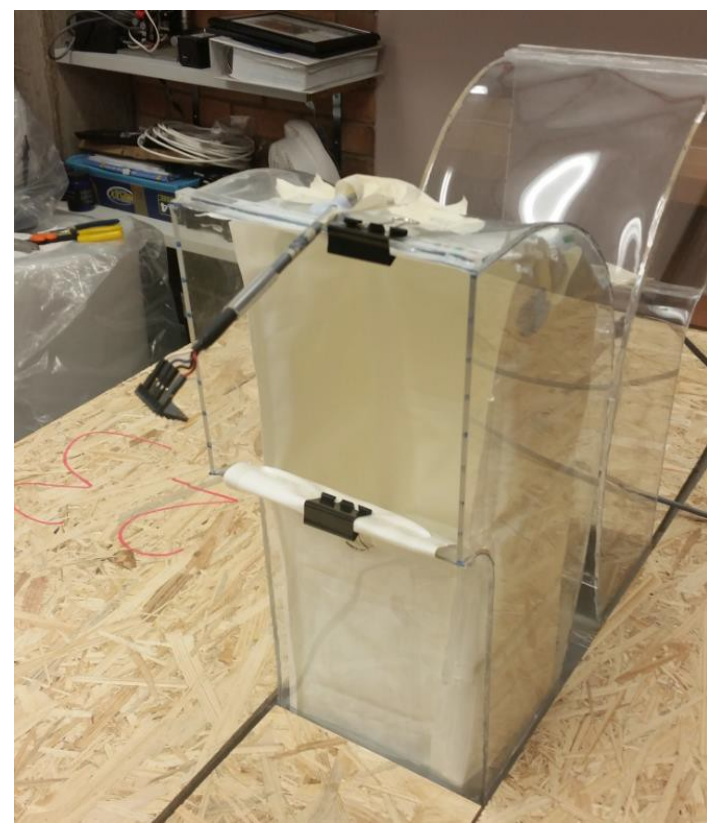

Figure 6. PCM covering the inlet windtunnel of the two sided windcatcher

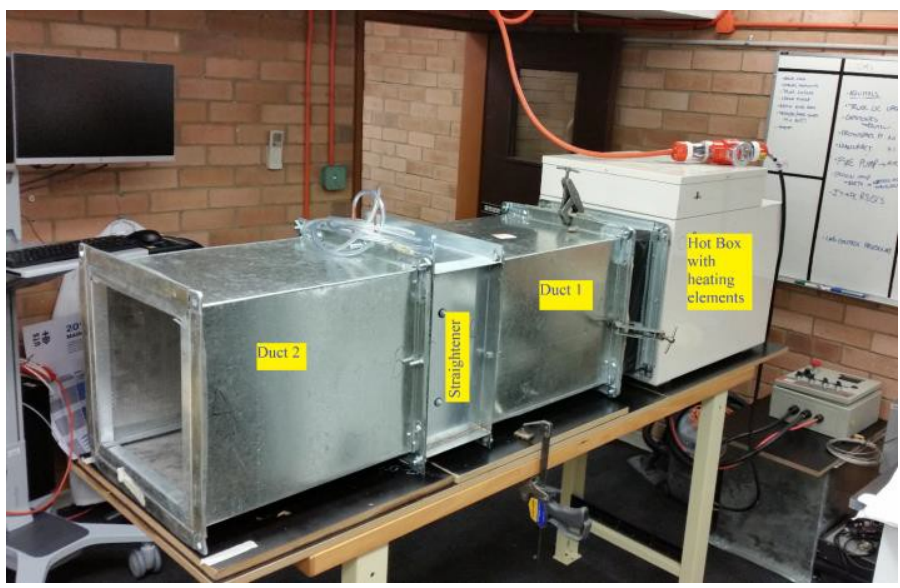

Figure 7. Set up for the Hot Box and ducts

Five BME sensors were distributed inside the chamber via the $12.7 \mathrm{~mm}$ holes from the right and left side sheets. Three sensors were inserted form the right side sheet, and two sensors from the left side sheet. The three sensors from the right are designated in the data acquisition system by Right front (Rt Fr), Right Back (Rt Bck) and Right Mid (Rt Mid), while the two sensors from the left side are designated by Left front (Lf Fr) and Left Back (Lf Bck). Four of these sensors (Rt Fr, Rt Mid, Lf Fr and Lf Bck) were placed at a height of $300 \mathrm{~mm}$ in the chamber. This height corresponds to $1.2 \mathrm{~m}$ high in a real sized room of $5 \times 4 \times 3 \mathrm{~m}^{3}$. The sensor Rt Bck was placed at $200 \mathrm{~mm}$ high in the chamber, which corresponds to a height of $0.8 \mathrm{~m}$ in a real sized room. The probe of these sensors was placed at 200 $\mathrm{mm}$ away from the corresponding right or left wall respectively. 
Two BME sensors were placed at the inlet and oulet of the windcatcher tunnel respectively. One sensor was placed at the inlet opening of the windcatcher slightly outside of the tunnel as shown in Figure 8. This sensor is used to measure the conditions of the air blown through the windcatcher. It is designated (In) in the data acquisition system. Another sensor was placed inside the windtunnel and near the outlet opening. It is designated (Out) in the data acquisition system and is used to measure the condition of the air exiting the windcatcher after circulating in the chamber.

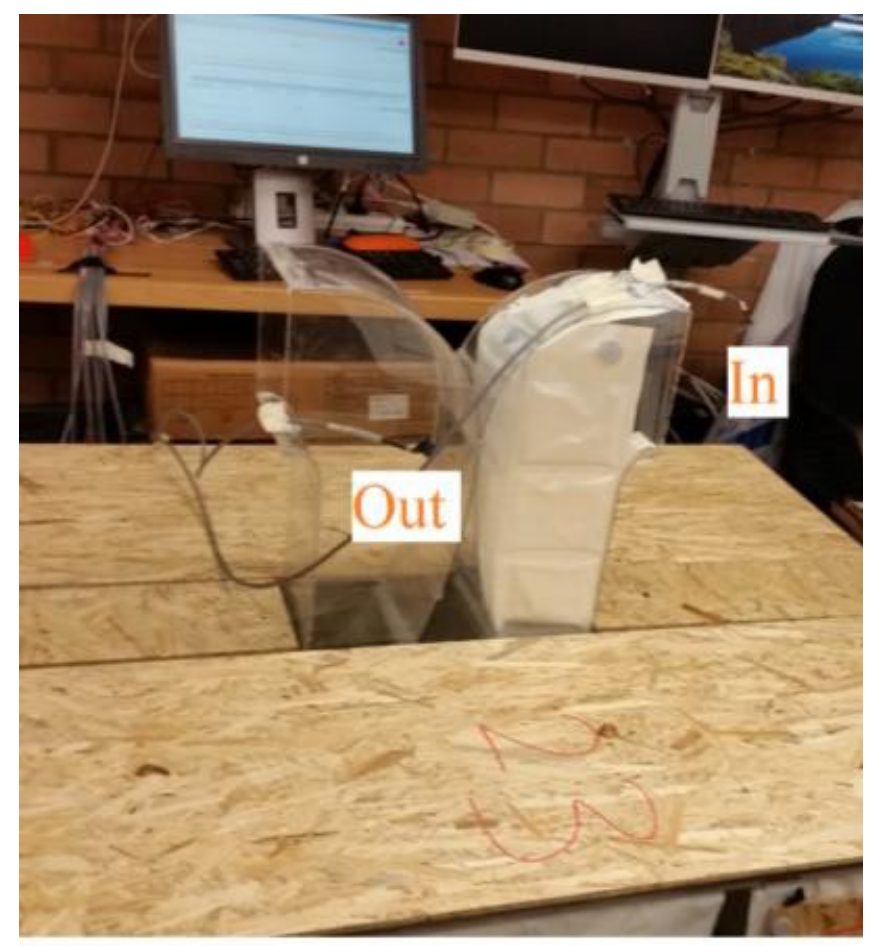

Figure 8. Set up shows (In and Out) sensors and the bench at the back where the Computer screen is placed.

The eighth sensor is placed outside and away of the acrylic chamber. It is placed on a bench close to the $\mathrm{Pi}$. This sensor is used to measure the ambient conditions in the laboratory and it is designated by (Amb) in the data acquisition system. Figure 8 shows the (In and Out) sensors as well as the bench at the back where the Computer screen, Rasbperry Pi and (Amb) sensors are placed.

To investigate the discharging process of the PCM, the hot box fan was operated with stage 1 which adds approximately $7^{\circ} \mathrm{C}$ to the ambient temperature in the lab. The fan was operated at full speed which corresponds to air velocity across the straightener of approximately $3.65 \mathrm{~m} / \mathrm{s}$. This velocity corresponds to a pressure difference of $8.15 \mathrm{~Pa}$ measured at the straightener.
To investigate the effect of phase change material incorporated with a windcatcher, different models with different locations of PCM have been used. Experiments have been conducted when the acrylic chamber is empty and when it contains PCM sheets. The following models have been investigated:

1. No PCM: chamber empty

2. PCM Full: PCM found on floor, ceiling and walls

3. PCM Full + windtunnel: PCM found on floor, ceiling, walls and the inlet windtunnel.

\section{RESULTS AND DISCUSSION}

Temperatures were recorded by the BME sensors during operation of the three models mentioned above. The experiments lasted at least 5 hours each.

Table 1 shows the temperatures recorded when the chamber is empty (No PCM) by the different sensors as well as the average of each sensor and the average of the room.

\begin{tabular}{|l|r|r|r|r|r|r|r|r|c|}
\hline \multirow{2}{*}{ No PCM } & \multicolumn{9}{|c|}{ Te mperature, $^{\circ}$ C } \\
\cline { 2 - 10 } & Amb H1 & \multicolumn{1}{|c|}{ In C8 } & Out E7 & Lf Fr G4 & Lf Bck F9 & Rt Fr B6 & $\begin{array}{c}\text { Rt Bck } \\
\text { D10 }\end{array}$ & Rt Mid A5 & $\begin{array}{c}\text { Room } \\
\text { Average }\end{array}$ \\
\hline start & 20.70 & 20.72 & 20.32 & 20.22 & 20.18 & 20.46 & 20.32 & 20.45 & 20.38 \\
\hline $15 \mathrm{~min}$ & 23.76 & 28.84 & 25.82 & 25.35 & 24.48 & 25.31 & 24.75 & 25.32 & 25.70 \\
\hline $30 \mathrm{~min}$ & 24.60 & 29.86 & 27.17 & 26.74 & 26.07 & 26.72 & 26.24 & 26.73 & 27.08 \\
\hline $45 \mathrm{~min}$ & 25.22 & 30.39 & 28.06 & 27.66 & 27.00 & 27.67 & 27.20 & 27.67 & 27.95 \\
\hline $60 \mathrm{~min}$ & 25.73 & 30.96 & 28.81 & 28.46 & 27.80 & 28.46 & 28.04 & 28.45 & 28.71 \\
\hline $75 \mathrm{~min}$ & 26.21 & 31.39 & 29.45 & 29.11 & 28.56 & 29.11 & 28.75 & 29.12 & 29.36 \\
\hline $90 \mathrm{~min}$ & 26.60 & 31.77 & 29.93 & 29.64 & 29.17 & 29.62 & 29.26 & 29.64 & 29.86 \\
\hline $105 \mathrm{~min}$ & 26.96 & 32.04 & 30.35 & 30.05 & 29.53 & 30.05 & 29.73 & 30.05 & 30.26 \\
\hline $120 \mathrm{~min}$ & 27.34 & 32.30 & 30.69 & 30.41 & 29.98 & 30.41 & 30.09 & 30.41 & 30.61 \\
\hline $135 \mathrm{~min}$ & 27.46 & 32.47 & 30.88 & 30.61 & 30.12 & 30.60 & 30.31 & 30.61 & 30.80 \\
\hline $150 \mathrm{~min}$ & 27.66 & 32.77 & 31.11 & 30.80 & 30.24 & 30.80 & 30.36 & 30.80 & 30.98 \\
\hline $165 \mathrm{~min}$ & 27.85 & 32.05 & 31.31 & 30.95 & 30.36 & 30.95 & 30.42 & 30.95 & 31.00 \\
\hline $180 \mathrm{~min}$ & 28.02 & 32.33 & 31.52 & 31.15 & 30.47 & 31.15 & 30.47 & 31.15 & 31.18 \\
\hline $195 \mathrm{~min}$ & 28.23 & 32.50 & 31.71 & 31.30 & 30.62 & 31.30 & 30.62 & 31.30 & 31.34 \\
\hline $210 \mathrm{~min}$ & 28.45 & 32.82 & 31.93 & 31.44 & 30.77 & 31.44 & 30.77 & 31.44 & 31.52 \\
\hline $225 \mathrm{~min}$ & 28.65 & 33.05 & 32.11 & 31.59 & 30.91 & 31.59 & 30.91 & 31.59 & 31.68 \\
\hline $240 \mathrm{~min}$ & 28.74 & 33.34 & 32.33 & 31.73 & 31.05 & 31.73 & 31.05 & 31.73 & 31.85 \\
\hline $255 \mathrm{~min}$ & 28.94 & 33.54 & 32.53 & 31.93 & 31.25 & 31.93 & 31.25 & 31.93 & 32.05 \\
\hline $270 \mathrm{~min}$ & 29.14 & 33.74 & 32.73 & 32.13 & 31.45 & 32.13 & 31.45 & 32.13 & 32.25 \\
\hline $285 \mathrm{~min}$ & 29.34 & 33.94 & 32.93 & 32.33 & 31.65 & 32.33 & 31.65 & 32.33 & 32.45 \\
\hline average & 26.98 & 31.54 & 30.08 & 29.68 & 29.08 & 29.69 & 29.18 & 29.69 & 29.85 \\
\hline
\end{tabular}

Table 1. Temperature readings for empty chamber (No PCM)

Table 2 shows the temperatures recorded when the chamber is full (PCM located on the floor, ceiling and walls) by the different sensors as well as the average of each sensor and the average of the room. Comparing this model with the previous model (No PCM), a reduction of average temperature in the room by about $2^{\circ} \mathrm{C}$ is observed.

Table 3 shows the temperatures recorded when the chamber is full plus windtunnel (PCM located on the floor, ceiling, walls and windtunnel) by the different sensors as well as the average of each sensor and the average of the room. Comparing this model with the previous two models, we observe about $0.7^{\circ} \mathrm{C}$ reduction in temperature with respect to the model with PCM Full while the reduction in average temperature with respect to No PCM is about $2.75^{\circ} \mathrm{C}$. 


\begin{tabular}{|l|c|c|c|c|c|c|c|c|c|}
\hline \multirow{3}{*}{ PCM Full } & \multicolumn{9}{|c|}{ Temperature, ${ }^{\circ}$ C } \\
\cline { 2 - 10 } & Amb H1 & In C8 & Out E7 & Lf Fr G4 & Lf Bck F9 & Rt Fr B6 & $\begin{array}{c}\text { Rt Bck } \\
\text { D10 }\end{array}$ & $\begin{array}{c}\text { Rt Mid } \\
\text { A5 }\end{array}$ & $\begin{array}{c}\text { Room } \\
\text { Average }\end{array}$ \\
\hline start & 19.80 & 20.80 & 20.09 & 20.01 & 19.90 & 19.91 & 20.12 & 20.22 & 20.15 \\
\hline $15 \mathrm{~min}$ & 22.68 & 27.89 & 24.68 & 24.50 & 23.89 & 24.42 & 23.72 & 24.51 & 24.80 \\
\hline $30 \mathrm{~min}$ & 23.44 & 28.70 & 25.52 & 25.35 & 24.76 & 25.30 & 24.57 & 25.33 & 25.65 \\
\hline $45 \mathrm{~min}$ & 24.01 & 29.27 & 26.12 & 25.95 & 25.34 & 25.90 & 25.17 & 25.96 & 26.24 \\
\hline $60 \mathrm{~min}$ & 24.51 & 29.63 & 26.54 & 26.40 & 25.80 & 26.37 & 25.71 & 26.37 & 26.69 \\
\hline $75 \mathrm{~min}$ & 24.89 & 29.96 & 26.86 & 26.76 & 26.20 & 26.76 & 26.02 & 26.74 & 27.04 \\
\hline $90 \mathrm{~min}$ & 25.22 & 30.27 & 27.17 & 27.10 & 26.49 & 27.08 & 26.30 & 27.09 & 27.36 \\
\hline $105 \mathrm{~min}$ & 25.60 & 30.44 & 27.37 & 27.35 & 26.74 & 27.34 & 26.57 & 27.32 & 27.59 \\
\hline $120 \mathrm{~min}$ & 25.83 & 30.65 & 27.56 & 27.63 & 26.98 & 27.61 & 26.85 & 27.56 & 27.83 \\
\hline $135 \mathrm{~min}$ & 26.04 & 30.93 & 27.86 & 27.89 & 27.26 & 27.89 & 27.10 & 27.84 & 28.11 \\
\hline $150 \mathrm{~min}$ & 26.33 & 31.15 & 28.16 & 28.13 & 27.46 & 28.14 & 27.33 & 28.07 & 28.35 \\
\hline $165 \mathrm{~min}$ & 26.53 & 31.27 & 28.32 & 28.25 & 27.50 & 28.26 & 27.50 & 28.21 & 28.47 \\
\hline $180 \mathrm{~min}$ & 26.62 & 31.44 & 28.48 & 28.46 & 27.75 & 28.41 & 27.70 & 28.37 & 28.66 \\
\hline $195 \mathrm{~min}$ & 26.90 & 31.55 & 28.84 & 28.91 & 28.30 & 28.91 & 28.21 & 28.94 & 29.09 \\
\hline $210 \mathrm{~min}$ & 27.03 & 31.67 & 29.07 & 29.13 & 28.47 & 29.16 & 28.40 & 29.18 & 29.30 \\
\hline $225 \mathrm{~min}$ & 27.27 & 31.83 & 29.47 & 29.34 & 28.67 & 29.34 & 28.46 & 29.17 & 29.47 \\
\hline $240 \mathrm{~min}$ & 27.44 & 32.01 & 29.71 & 29.50 & 28.90 & 29.55 & 28.69 & 29.40 & 29.68 \\
\hline $255 \mathrm{~min}$ & 27.64 & 32.21 & 29.91 & 29.70 & 29.10 & 29.75 & 28.89 & 29.60 & 29.88 \\
\hline $270 \mathrm{~min}$ & 27.84 & 32.41 & 30.11 & 29.90 & 29.30 & 29.95 & 29.09 & 29.80 & 30.08 \\
\hline $285 \mathrm{~min}$ & 28.04 & 32.61 & 30.31 & 30.10 & 29.50 & 30.15 & 29.29 & 30.00 & 30.28 \\
\hline average & 25.68 & 30.33 & 27.61 & 27.52 & 26.92 & 27.51 & 26.78 & 27.48 & 27.74 \\
\hline
\end{tabular}

Table 2. Temperature readings for chamber with PCM full

\begin{tabular}{|l|r|r|r|r|r|r|r|r|r|}
\hline $\begin{array}{l}\text { PCM Full } \\
\begin{array}{c}\text { plus } \\
\text { Windtunnel }\end{array}\end{array}$ & \multicolumn{1}{|c|}{ Amb H1 } & In C8 & Out E7 & Lf Fr G4 & Lf Bck F9 & Rt Fr B6 & $\begin{array}{c}\text { Rt Bck } \\
\text { D10 }\end{array}$ & $\begin{array}{c}\text { Rt Mid } \\
\text { A5 }\end{array}$ & $\begin{array}{c}\text { Room } \\
\text { Average }\end{array}$ \\
\hline start & 19.86 & 20.56 & 19.64 & 19.29 & 19.25 & 19.18 & 19.42 & 19.55 & 19.56 \\
\hline $15 \mathrm{~min}$ & 22.64 & 27.90 & 23.32 & 22.88 & 21.99 & 22.61 & 22.20 & 22.92 & 23.40 \\
\hline $30 \mathrm{~min}$ & 23.44 & 28.93 & 24.42 & 23.95 & 23.06 & 23.70 & 23.25 & 23.97 & 24.47 \\
\hline $45 \mathrm{~min}$ & 24.00 & 29.58 & 25.22 & 24.75 & 23.88 & 24.49 & 23.82 & 24.73 & 25.21 \\
\hline $60 \mathrm{~min}$ & 24.62 & 30.15 & 25.81 & 25.34 & 24.45 & 25.18 & 24.53 & 25.31 & 25.82 \\
\hline $75 \mathrm{~min}$ & 25.03 & 30.61 & 26.29 & 25.85 & 24.92 & 25.69 & 24.97 & 25.81 & 26.31 \\
\hline $90 \mathrm{~min}$ & 25.39 & 30.91 & 26.70 & 26.19 & 25.30 & 26.08 & 25.34 & 26.14 & 26.67 \\
\hline $105 \mathrm{~min}$ & 25.71 & 31.17 & 27.06 & 26.56 & 25.59 & 26.38 & 25.65 & 26.49 & 26.99 \\
\hline $120 \mathrm{~min}$ & 26.03 & 31.46 & 27.37 & 26.86 & 25.87 & 26.73 & 25.88 & 26.81 & 27.28 \\
\hline $135 \mathrm{~min}$ & 26.32 & 31.67 & 27.63 & 27.13 & 26.21 & 27.06 & 26.16 & 27.07 & 27.56 \\
\hline $150 \mathrm{~min}$ & 26.59 & 31.83 & 27.90 & 27.38 & 26.46 & 27.29 & 26.47 & 27.33 & 27.81 \\
\hline $165 \mathrm{~min}$ & 26.78 & 32.02 & 28.11 & 27.62 & 26.67 & 27.58 & 26.62 & 27.55 & 28.02 \\
\hline $180 \mathrm{~min}$ & 27.02 & 32.22 & 28.37 & 27.88 & 26.85 & 27.84 & 26.88 & 27.77 & 28.26 \\
\hline $195 \mathrm{~min}$ & 27.22 & 32.44 & 28.60 & 28.13 & 27.05 & 28.11 & 27.12 & 28.06 & 28.50 \\
\hline $210 \mathrm{~min}$ & 27.38 & 32.56 & 28.82 & 28.30 & 27.34 & 28.36 & 27.35 & 28.24 & 28.71 \\
\hline $225 \mathrm{~min}$ & 27.65 & 32.73 & 29.09 & 28.59 & 27.58 & 28.58 & 27.55 & 28.43 & 28.94 \\
\hline $240 \mathrm{~min}$ & 27.77 & 32.84 & 29.26 & 28.78 & 27.73 & 28.86 & 27.72 & 28.66 & 29.12 \\
\hline $255 \mathrm{~min}$ & 27.85 & 32.99 & 29.51 & 28.98 & 27.97 & 29.06 & 27.95 & 28.88 & 29.33 \\
\hline $270 \mathrm{~min}$ & 28.10 & 33.13 & 29.75 & 29.27 & 28.21 & 29.33 & 28.08 & 29.12 & 29.56 \\
\hline $285 \mathrm{~min}$ & 28.25 & 33.29 & 29.98 & 29.49 & 28.43 & 29.59 & 28.43 & 29.38 & 29.80 \\
\hline average & 25.88 & 30.95 & 27.14 & 26.66 & 25.74 & 26.59 & 25.77 & 26.61 & 27.07 \\
\hline
\end{tabular}

Table 3. Temperature readings for chamber with PCM full plus windtunnel

Figure 9 summarizes the results presented in Tables 1, 2 and 3 showing the box plot for the three models. It shows the average temperature inside the chamber as well as the minimum and maximum temperatures and the corresponding mean values. The minimum and maximum temperatures are those found in the corresponding table related to each model.

The model with the PCM located in the floor, ceiling and walls as well as in the wind tunnel has shown the best performance compared to the other two models and the reduction of temperatures observed is significant with respect to the model with No PCM.

\section{Stage 1 / Fan speed $100 \%$}

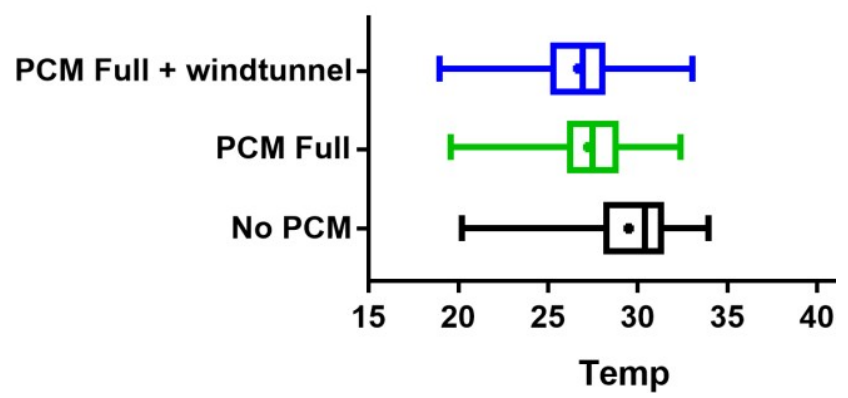

Figure 9. Box plot of the three models studied showing the average temperature of all the sensors in the room and themean values.

Figure 10 shows the plot of recorded temperatures by the BME sensors for the room with PCM full plus windtunnel. The highest trace is the temperature at the inlet of the windcacther tunnel while the lowest temperature is the ambient temperature in the lab.

\section{CONCLUSION}

The effect of phase change material PCM on the temperature in a room fitted with a windcatcher is investigated. PCM is integrated respectively at the walls of the room, its floor and ceiling and within the windcatchers inlet tunnel. Three models are investigated and compared, one model when the room is empty (No PCM), the second model is when the room is full with PCM (PCM on floor, walls and ceiling), and the third model is when the PCM is full plus located in the inlet windtunnel of the windcatcher.

Wind is blown through the room using a fan with heating elements and the temperature is measured at different locations inside the chamber. Average temperatures corresponding to the different models are compared.

The model with the PCM located in the floor, ceiling and walls as well as in the wind tunnel has shown the best performance compared to the other two models and the reduction of temperatures observed is significant (about $2.75{ }^{\circ} \mathrm{C}$ ) with respect to the model with No PCM.

Future work will experimentally study the effect of incorporating PCM on the humidity levels in a room fitted with a windcatcher. Three dimensional CFD simulation of the effect of PCM in a windcatcher may also be conducted.

\section{ACKNOWLEDGMENTS}

This research is supported by an Australian Government Research Training Program Scholarship. 


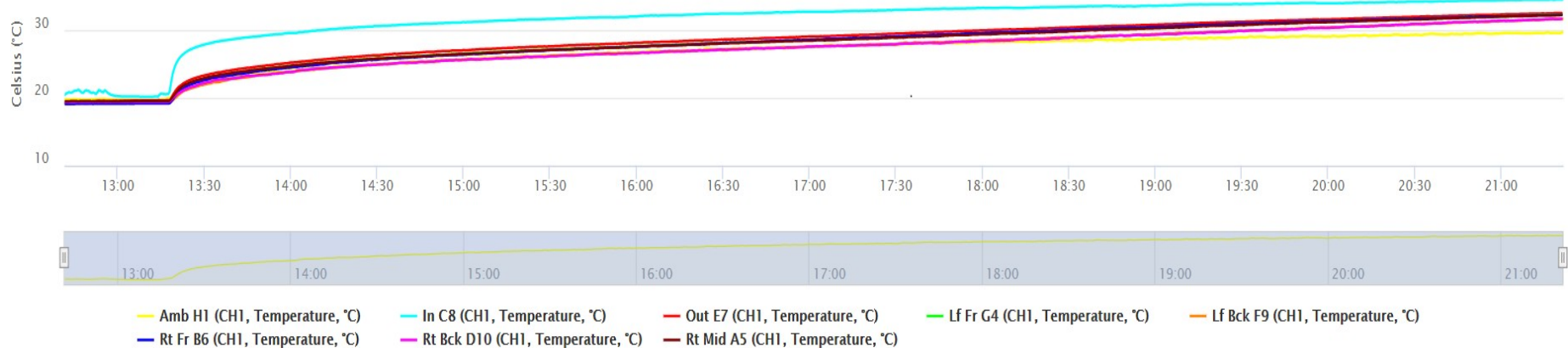

Figure 10. Temperature plots for room with PCM full plus windtunnel.

\section{REFERENCES}

[1] Dallimer, M., Z. Tang, P.R. Bibby, P. Brindley, K.J. Gaston, and Z.G. Davies, Temporal changes in greenspace in a highly urbanized region. Biology Letters, 2011. 7(5): p. 763-766.

[2] Irga, P.J., P. Abdo, M. Zavattaro, and F.R. Torpy, An assessment of the potential fungal bioaerosol production from an active living wall. Building and Environment, 2017. 111: p. 140-146.

[3] Irga, P.J., N.J. Paull, P. Abdo, and F.R. Torpy, An assessment of the atmospheric particle removal efficiency of an in-room botanical biofilter system. Building and Environment, 2017. 115: p. 281-290.

[4] Pettit, T., P.J. Irga, P. Abdo, and F.R. Torpy, Do the plants in functional green walls contribute to their ability to filter particulate matter? Building and Environment, 2017. 125(Supplement C): p. 299-307.

[5] Abdo, P., B.P. Huynh, and V. Avakian. Distribution of Air Flow Through a Green Wall Module. in ASME 2017 Fluids Engineering Division Summer Meeting. 2017. Waikoloa, Hawaii, USA: American Society of Mechanical Engineers.

[6] Abdo, P., B.P. Huynh, and V. Avakian. EFFECT OF FAN SPEED ON AIR FLOW THROUGH A GREEN WALL MODULE. in Proceedings of the ASME 2018 5th Joint US-European Fluids Engineering Summer Conference FEDSM2018. 2018. July 15-20, 2018, Montreal, Quebec, Canada: American Society of Mechanical Engineers.
[7] Abdo, P., B.P. Huynh, V. Avakian, T. Nguyen, J. Gammon, F.R. Torpy, and P.J. Irga. Measurement of air flow through a green-wall module. in 20th Australasian Fluid Mechanics Conference. 2016. Perth, Australia.

[8] Abdo, P., B.P. Huynh, and V. Avakian. Effect of Green Wall Modules on Air Temperature and Humidity. in Proceedings of the ASME 2018 5th Joint USEuropean Fluids Engineering Summer Conference FEDSM2018. 2018. July 15-20，2018， Montreal, Quebec, Canada: American Society of Mechanical Engineers.

[9] Abdo, P. and B.P. Huynh. Effect of Passive Green Wall Modules on Air Temperature and Humidity. in Proceedings of the ASME 2018 International Mechanical Engineering Congress and Exposition IMECE2018. 2018. November 9-15, 2018, Pittsburgh, PA, USA: American Society of MechanicalEngineers.

[10] Abdo, P., B.P. Huynh, P.J. Irga, and F.R. Torpy, Evaluation of air flow through an active green wall biofilter. Urban Forestry \& Urban Greening, 2019. 41: p. $75-84$.

[11] Souayfane, F., P.H. Biwole, F. Fardoun, and P. Achard, Energy performance and economic analysis of a TIMPCM wall under different climates. Energy, 2019. 169: p. 1274-1291.

[12] Souayfane, F., F. Fardoun, and P.-H. Biwole, Phase change materials (PCM) for cooling applications in buildings: A review. Energy and Buildings, 2016. 129: p. 396-431. 
[13] Soares, N., J.J. Costa, A.R. Gaspar, and P. Santos, Review of passive PCM latent heat thermal energy storage systems towards buildings' energy efficiency. Energy and Buildings, 2013. 59: p. 82-103.

[14] Waqas, A. and Z. Ud Din, Phase change material (PCM) storage for free cooling of buildings-A review. Renewable and Sustainable Energy Reviews, 2013. 18: p. 607-625.

[15] Butala, V. and U. Stritih, Experimental investigation of PCM cold storage. Energy and Buildings, 2009. 41(3): p. 354-359.

[16] Baetens, R., B.P. Jelle, and A. Gustavsen, Phase change materials for building applications: A state-ofthe-art review. Energy and Buildings, 2010. 42(9): p. 1361-1368.

[17] Tyagi, V.V. and D. Buddhi, PCM thermal storage in buildings: A state of art. Renewable and Sustainable Energy Reviews, 2007. 11(6): p. 1146-1166.

[18] Zhou, D., C.Y. Zhao, and Y. Tian, Review on thermal energy storage with phase change materials (PCMs) in building applications. Applied Energy, 2012. 92: p. 593-605.

[19] Verma, P., Varun, and S.K. Singal, Review of mathematical modeling on latent heat thermal energy storage systems using phase-change material. Renewable and Sustainable Energy Reviews, 2008. 12(4): p. 999-1031.

[20] Zhang, Y., K. Lin, Q. Zhang, and H. Di, Ideal thermophysical properties for free-cooling (or heating) buildings with constant thermal physical property material. Energy and Buildings, 2006. 38(10): p. 1164-1170.

[21] Abhat, A., Low temperature latent heat thermal energy storage: Heat storage materials. Solar Energy, 1983. 30(4): p. 313-332.

[22] Akeiber, H., P. Nejat, M.Z.A. Majid, M.A. Wahid, F. Jomehzadeh, I. Zeynali Famileh, J.K. Calautit, B.R. Hughes, and S.A. Zaki, A review on phase change material (PCM) for sustainable passive cooling in building envelopes. Renewable and Sustainable Energy Reviews, 2016. 60: p. 1470-1497.

[23] Ramakrishnan, S., X. Wang, M.Alam, J. Sanjayan, and J. Wilson, Parametric analysis for performance enhancement of phase change materials in naturally ventilated buildings. Energy and Buildings, 2016. 124: p. 35-45.

[24] Álvarez, S., L.F. Cabeza, A. Ruiz-Pardo, A. Castell, and J.A. Tenorio, Building integration of PCM for natural cooling of buildings. Applied Energy, 2013. 109: p. 514-522.

[25] Mosaffa, A.H., C.A. Infante Ferreira, F. Talati, and M.A. Rosen, Thermal performance of a multiple PCM thermal storage unit for free cooling. Energy Conversion and Management, 2013. 67: p. 1-7.

[26] Hughes, B.R. and S.A.A.A. Ghani, Investigation of a windvent passive ventilation device against current fresh air supply recommendations. Energy and Buildings, 2008. 40(9): p. 1651-1659.

[27] Abdo, P. and B.P. Huynh. Effect of Combining Buoyancy Driven and Winddriven Ventilation in a Two Dimensional Room Fitted With a Windcatcher. in Proceedings of the ASME International Mechanical Engineering Congress and Exposition. 2017. Tampa, Florida, USA, November 3-9, 2017: American Society of Mechanical Engineers.

[28] Abdo, P., R. Taghipour, and B.P. Huynh. EFFECT OF WINDCATCHER'S INLET SHAPE ON VENTILATION FLOW THROUGH A TWO DIMENSIONAL ROOM. in Proceedings of the ASME 2018 5th Joint US-European Fluids Engineering Summer Conference FEDSM2018. 2018. July 15-20, 2018, Montreal, Quebec, Canada: American Society of Mechanical Engineers.

[29] Abdo, P., R. Taghipour, and B.P. Huynh. Simulation of Buoyancy Driven and Winddriven Ventilation Flow in a Three Dimensional Room Fitted with a Windcatcher. in 21st Australasian Fluid Mechanics Conference. 2018. Adelaide, Australia.

[30] Taghipour, R., P. Abdo, and B.P. Huynh. EFFECT OF WIND SPEED ON VENTILATION FLOW THROUGH A TWO DIMENSIONAL ROOM FITTED WITH A WINDCATCHER. in Proceedings of the ASME 2018 International Mechanical Engineering Congress and Exposition IMECE2018. 2018. November 9-15, 2018, Pittsburgh, PA, USA: American Society of Mechanical Engineers. 